\title{
saience\& society
}

\section{Therise of a culture of life}

\author{
The biological sciences are encouraging the move away from theideals of the Enlightenment towards an idea \\ of individual perfectibility and enhancement
}

\section{KarinKnorrCetina}

$\mathrm{T}$ he Enlightenment age celebrated the human ideals of rationality, potential, freedom, equality and justice. These ideals included the belief in science as a means to improve human existence. They lie at the root of the belief in the perfectibility of, and salvation by, society-the moral underpinning of the social sciences. By contrast, what the biological sciences promise is the perfectibility of life in the form of life enhancement and extension. Whereas the concepts of humanity and humanism have inspired intellectual elites and scientific disciplines for centuries, today the notion of life replaces the notion of the human as a concept that bridges developments in several sciences and in practical discourses.

\section{... what the biological sciences promise is the perfectibility of life in the form of life enhancement and extension}

'Life' stands for an open-ended series of biological, psychological, economic and even phenomenological significations and processes. What it does not stand for is the further expansion of Enlightenment ideals of human reason and social salvation. I argue that we are experiencing a turn to a 'culture of life' in a broad and encompassing sense that is comparable to the way in which humancentred ideas once dominated our thinking. This development coincides with historical changes through which the culture of the human and of society that was based on Enlightenment ideals empties out into a postsocial era. I also claim that these ideas are deeply rooted in the biological sciences from which they draw motivation. Although a culture of life stems from biology, it is also nourished and sustained by a large number of processes and transitions. I also briefly argue that the concept of a promise that underlies a culture of life entails shifts in responsibility and temporal orientation that need to be discussed. Some of these shifts are already apparent in political and other debates.

$S_{\text {so }}^{\text {tu }}$ ociality is likely to be a permanent feature of human life. But the forms of sociality are changing, and the regions of social structuring may expand or contract in conjunction with historical developments. Modernity has often been associated with the collapse of community and tradition and the onset of individualization. Central to our experience today are similar retractions of social principles in different areas of life. These are not usually discussed together, and they do not have the same roots. But they work together in doing away with previous categories of social imagination, and in creating the space in which a postsocial imagination can take hold (Knorr Cetina, 1997).

The first major expansion of social principles during the nineteenth century and throughout the early decades of the twentieth century was that of social policies, which was linked to the rise of the nation state. Today's social policies stem from the 'nationalization of social responsibility' - the formulation of social rights alongside individual rights and the role of

\section{Social explanations and social thinking have to prove their worth against, among other things, biological and economical descriptions of human behaviour}

the state as the 'natural container' and provider of labour regulations, pension and welfare provisions, unemployment insurance and public education. A second expansion, which is connected to the first, took place in social thinking and social imagination. The institutionalization of social policies created new concepts of the forces that determine human destiny: they were thought of as impersonal, social forces. Rather than assuming the automatic adaptation of individuals to changing environmental conditions, these ideas focused on prevailing imbalances and their social causes.

A third area in which social principles and structures expanded was that of social organization. The rise of the nation state implied an increase in bureaucratic institutions. Industrialization brought with it the emergence of the factory and the modern corporation. Industrial, nationstate societies are therefore unthinkable without complex organizations, which act as localized social arrangements to manage work and services by structural means. A fourth area of expansion was that of social structure. The class differentiation of modern society is itself an outgrowth of the industrial revolution and its political consequences, as well as a product of processes of social and political measurement and categorization. 
It is obvious today that these expansions of social principles and socially constituted environments have come to a halt. In many European countries and the USA, the welfare state, with all its manifestations of social policy and collective insurance against individual disaster, is in the process of being 'overhauled'-some would say 'dismantled'. Thatcherism in the UK and 'neo-liberalism' in general could be viewed as partially successful attempts to contest some of the social rights that were acquired in the previous century. Social explanations and social thinking have to prove their worth against, among other things, biological and economical descriptions of human behaviour. The mobilization of social imagination was an attempt to identify the collective basis for individuals' predicaments and dispositions to react. This collective basis is now more likely to be found in the similarity of the genetic make-up of socially unrelated members of the population. Social structures also seem to be losing some of their hold. When complex organizations are dissolved into networks of smaller, independent profit centres, some of the hierarchically organized social systems get lost along the way. When personal service is replaced by automated electronic service, no social structures at all are required-only electronic information structures. The expansion of societies on a global scale does not imply further expansions of social complexity. Instead, genuinely global forms may become feasible only if they avoid complex institutional structures.

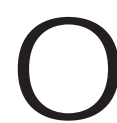

ne of the most important elements in the development described so far may well be the loss of social imagination-the slow erosion of the belief in salvation by society. This idea involved not only the idea of impersonal social forces affecting the individual but also the notion of universal human perfection through society. It was put forward by Rousseau and Enlightenment thinkers such as Condorcet, who announced the possibility of increasingly rapid progress towards a perfect form of human society that is marked by "the abolition of inequality between nations, the progress of equality within each nation, and the true perfection of mankind" (Condorcet, 1955). The notion is also epitomized by Marx' vision of a socialist age, which he thought would

\section{This focus on the individual prepares the ground... for the emergence of a notion of life that can be seen as a link between the human and the natural sciences}

begin once capitalism reached its peak and collapsed under its own self-created contradictions. The collapse of Marxism as a creed signifies the end of the belief in salvation by society, and the end of a social imagination that transposed itself into what Peter Drucker called a "secular religion" (D rucker, 1993). The question then is what replaces the social imagination. In the sciences that focus on the human world, the answer is plain: it is now the individual rather than society. This focus on the individual prepares the ground, I maintain, for the emergence of a notion of life that can be seen as a link between the human and the natural sciences.

The claim that the social imagination of the past is being superseded by a focus on the individual can be linked to several developments. First, even from within the state itself, voices have emerged that advocate individual self-reliance in regard to personal welfare and encourage non-governmental avenues to the achievement of collective goals. One illustration of this is the model of a de-institutionalized welfare state and a socialism that reinstitutes individual responsibility while curtailing social rights and welfare programmes.

Second, just as a social mentality was elaborated and extended by social science, ideas focusing on the individual are unfolded by particular disciplinary traditions. O ne example is the rise of rational choice theories, which draw on concepts of utility maximization in economics that have been imported into other sciences. These theories empower the individual as the unit that seeks information, calculates behavioural outcomes, and, through these mechanisms, engineers his or her fate. The exaggerated emphasis on instrumental reason and information, and the attempt to translate collective and cooperative choices into individual utilities may not be warranted by data or plausible argument, but these imaginaries of rational behaviour are also the ones that empower subjectivity thinking and cast doubt on social thinking. Third, subjectivity thinking and subjectivity imagination are manifest in the vast numbers of self-help books and manuals that counsel individuals on self-improvement and help them to discover themselves.

However, there is more involved in subjectivity thinking than the onslaught of a new wave of individualization. The selfhelp literature consistently asserts an individual's right and obligation to make a strong commitment to him/herself. But it also affirms that it is a person's 'life' that should be improved; the goal of the commitment to oneself is life enhancementan idea that not only means increased enjoyment but also reflects on biological life as improvable and extendable. Subjectivity thinking in the social and psychological sciences and in practical reasoning includes the notion of individual life, life extension and anti-ageing projects as relevant to self-oriented behaviour.

\section{... the goal of the commitment to oneself is life enhancement...}

The notion of the individual subject has itself become redefined in current thinking and is now less divided from nature or non-human objects than it was before. Enlightenment thinkers drew the 'circle of humanity' tightly, defining subjects in terms of their capacity to exercise agency. Sciences today-psychoanalysis, cognitive and evolutionary psychology, the psychology of emotions, behavioural economics and biology-draw the circle more widely as they make claims about the unconscious and emotional sides of the individual, human decision biases and human intelligence. Behavioural economists, such as Richard Thaler, have suggested that as assumptions about rationality give way to research into human cognition, Homo sapiens loses IQ and gains visceral definition. The remarkable rise of subjectivity thinking thus harbours tendencies that bridge the gap between the human and the natural sciences. One tendency is the orientation towards concepts such as the notion of life. The second tendency is the orientation towards research and explanations that assimilate humans with other forms of life. Both play into a more general culture of life. 


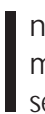
now want to address life-centred ideas more directly and argue that they span several disciplines and practical areas. The notion of life serves as a metaphor to illustrate a cultural turn to nature and to replace the culture of the human and the social. What has become thinkable today, in a break with Enlightenment ideals, is not the perfectibility of human society by societal means or the cognitive and ethical perfectibility of the human, but the perfectibility of life-through life enhancement, life extension and anti-ageing possibilities on the individual level, but also through the biopolitics of populations, the protection and reflexive manipulation of nature, and the idea of intergenerational rather than distributional justice.

O ne massive source of fantasies that fuel a culture of life and challenge traditional humanism is the biological sciences themselves. They produce a stream of research that inspires elaborations of the human individual as enriched by genetic, biological and biotechnological supplements and upgrades. These ideas relate to the enhancement of life through preimplantation genetic diagnosis and screening, germline engineering, psychotropic drugs that improve emotions and self-esteem, biotechnological and other means, and human cloning.

Serious research money goes into halting and reversing ageing processes, and gives us the option of extending our physical and intellectual capacities beyond present levels. It is not surprising that antiageing and life extension capture the imagination like no other life-enhancing project; it is close to the concerns of the individual, for whom the struggle with the certainty of death is in some sense central to what it means to be human. Personal death has long been a prominent topic of art and religion, philosophical thought and literature. Life beyond death is arguably a motivating force in the struggle for human recognition; the promise of life after death is the basis of the Christian religion, and Enlightenment ideals as well as evolutionary thought can be seen as models for overcoming individual death by means of collective rationality and the reproductive success of populations. This understanding of life in Western and Christian thought is challenged today. The biological sciences promise a notion of life that is not determined by an irreversible process of ageing and the certainty of death, but is understood in terms of the indefiniteness brought about by life extension and antiageing research.

Substituting indefiniteness (life extension) for certainty (death) may seem like a small step. But it is a quantum leap when it comes to the most definite human existential conditions, which I hold to be ageing and death. Perhaps for the first time in history, biology is not destiny; instead, the biological sciences themselves promise life as a creative accomplishment and constructive project. This challenges religious beliefs and moral commitments, in addition to contemporary social and economic institutional structures, generational relationships and dominance hierarchies. But it also activates what may become one of the greatest hopes of the twenty-first centuryprogress towards increased longevity and the counteraction of age-related deterioration. The debates that surround the biological sciences bring into focus the perfectibility of individual life. As a consequence, a changed definition of cultural life is shaped not by the prospect of death but by the possibility of life enhancement and perfection.

\section{One massive source of fantasies that fuel a culture of life and challenge traditional humanism isthe biological sciences themselves}

The biological sciences are central to this thinking, but the respective ideas also pervade other fields. The extent to which this happens is illustrated by those areas that view human beings as on the verge of being transformed into cyborgs (Haraway, 1991), posthumans (Fukuyama, 2002) or transhumans (Baard, 2003). These creatures are human descendants that have been improved by bioengineering in combination with nanotechnology, the information sciences and cognitive research (the 'NBIC' group of sciences). The NBIC sciences converge to develop devices that enhance or 'augment' biological human nature, often in the direction of life extension. They pose a challenge by questioning the sharp distinctions between humans and machines, by appealing to the plasticity of the organic and the technical. NBIC research creates interfaces between these categories that blur the human/non-human distinction.

Because most of the technologies now implanted into humans or used as replacement parts for malfunctioning organs have medical and life-extending functions, it seems likely that the NBIC sciences will create opportunities to enhance normal human performance, especially in older age groups. Performance enhancements might comprise an expanded memory capacity, implanted links for direct access to telecommunication networks, much faster thinking speed or the capacity to see in the infrared and ultraviolet wavelengths. Such 'improvements' are not within immediate reach, but they may well be realized. Overcoming genetic diseases, congenital birth defects and many other causes of human suffering, and particularly overcoming the normal predicaments of old age and perhaps death, also provide motivation for the creation and testing of relevant devices.

Developments of this sort raise many questions about the rights of transhumans and the ethics expected from them. Will those with a higher percentage of prosthetic parts or certain kinds of machine parts have fewer rights than biological cell structures? Why should biological cell structure serve as a criterion for drawing a distinction between human and non-human beings? What will it mean if life-extending technologies together with shrinking birth rates massively increase the population of older people? How will political powers and social institutions have to change under such circumstances? W hat are the implications for families when collateral relativessuch as siblings, aunts and uncles-are replaced by the simultaneous existence of four or five generations of parents and children (Fukuyama, 2002)? We may consider such questions far off, the progress towards these developments as overestimated, and those who believe in the posthuman challenge as out of touch with reality. But I claim that the fantasies themselves are important. They play into and help create what I call a culture of life.

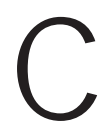
onsider now other areas of discussion. I have already pointed out that in the social sciences, 'life' thinking may be implicated in those areas that have turned the individual and its search for ego into topics of investigation. But a more direct incidence of a life-centred notion in the social sciences is the recent renaissance 


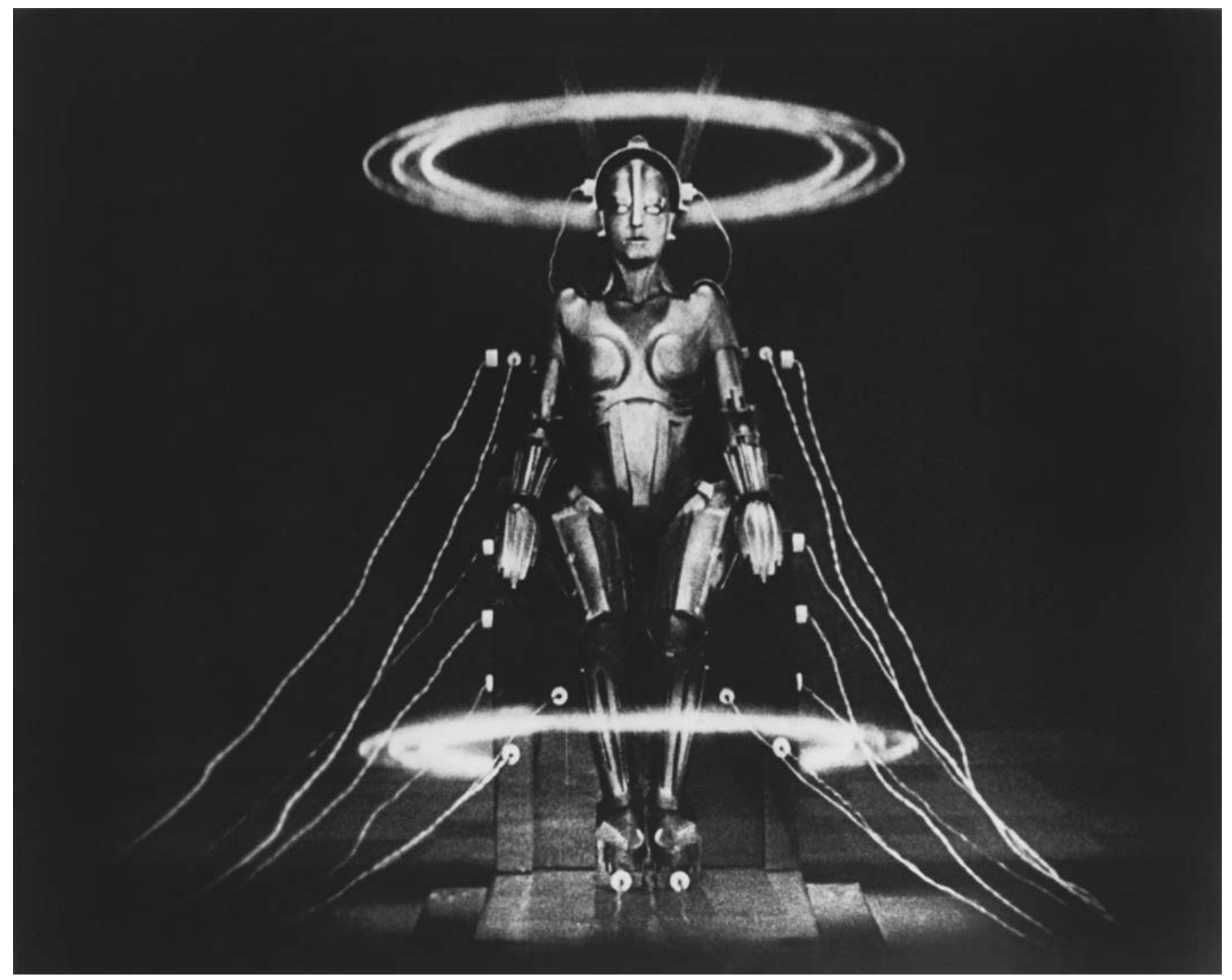

Fritz Lang (1926) BrigitteH elm as the Robot M aria in 'M etropolis'. @ Bettmann/CORBIS

of the notion of a generation. It serves as the antithesis to the common concept of solidarity that was favoured by social democratic and socialist parties in the past 100 years, which is based on equality through the redistribution of resources. By contrast, generational concepts focus on individuals who are sequentially related through family ties-in correspondence with the hopes for life extension and anti-ageing. What supports these ideas are institutional changes in pension schemes that move from solidaritybased principles, in which income from the working population is redistributed to retirees, to personal investment schemes in which one plans and pays for one's retirement benefits over the course of a lifetime. On a more conceptual and theoretical level, a return to human-nature-based theories of rights and justice can be associated with life-centred ideas (Fukuyama, 2002), as can Heidegger's temporal ideas of human existence as "being towards death" (Heidegger, 1962).

On a popular level, life-enhancement literature, the bioethical controversies about the rights to live genetically and technologically enriched lives and the images of individuals searching for optimal life experience suggest that individuals and populations are deeply involved in the appropriation of their lives and those of their offspring. Conflicts over the "appropriation of life" (Lash, 2003) rather than over the appropriation of surplus value may well be what defines posthuman and postsocial environments. he language of humanism that pervades Enlightenment ideas was not predisposed to accepting posthuman developments that are centred on life. Nor was it predisposed to accept the expanding role of biological and technological augmentations of human nature. In particular, the language of humanism is not predisposed to the orientation to a future that is informed by continually emerging and constructed promises- rather than important and stable values- that characterize a culture of life. In speech act theory, which explains how language is used to accomplish goals, the conditions of success of a request-such as humanism's request for virtue and ethical behaviour and Enlightenment's request for reason and 


\section{saience\& society}

rationality-are quite different from the conditions of a promise. Promises must concern future acts and things that the promise receiver really wants, and they imply that the promise giver is able to and intends to keep the promise. Thus a promise giver's competence, and trust in his or her sincerity, as well as the future, have a role if a promise is to be successful. Fulfilment of the promise is the task of the promise giver, not of the promise receiver. We can contrast the promise scenario with that of requests, where fulfilment is the task of the receiver of the request. The wants or desires of the receiver have no role in the matter, and the future is only implicated in a trivial way-as when I ask someone to pass the salt and the passing has to be done after the demand is uttered.

A promise-based culture would seem to be more seductive than a request-based culture. First, it works with people's desires, to which it pays attention and which it stimulates. Many of the life-enhancing propositions that the biological sciences, in conjunction with others, put before us pertain to deep-felt desires within W estern cultures-the desire to alleviate illness and disease, to augment mental capacities and bodily appearance, and most importantly, to escape ageing and death. Second, because fulfilment of the promise and the requirement of sincerity lie with the promise giver, all the promise receiver needs to contribute are plausible wants. Third, in the present case, the promise givers are in many cases the sciences. The sciences are of course not untainted by public criticism, but when it comes to belief in their sincerity and in their capacity to fulfil the promises they make, society trusts them more than it would trust politicians, for example.

Enlightenment thinking was based not only on requests but also on promises-of equality, liberty and justice. The promise giver was the state, which took on the task of securing public welfare. However, today's Western states are gradually withdrawing from the role as the promise giver and are increasingly unable to fulfil its demands; states simply lose power in a global age. Much promising has shifted, I maintain, away from the state, although requests and demands have not shifted elsewhere. States also operate increasingly out of synchrony with the promises and delivered results of the sciences.

T he move to a culture of life implies changes in regard to the source and defining concepts- the human versus life- of our collective imagination. This examination shines the analytical light on these changes, as well as on a confluence of developments in many areas that entail the rise of a culture of life. These changes are larger and run deeper than the concrete ethical questions that the biological sciences raise. I have suggested that they also indicate a sharp break with the Enlightenment ideals of human reason and the perfectibility of society, which they have replaced with the idea of the perfectibility of life.

\section{REFEREN CES}

Baard E (2003) Cyborg Liberation Front. Inside the M ovement for Posthuman Rights. The Village

Voice, Jul 30. www.villagevoice.com

Condorcet M (1955) Sketch for a H istorical

Picture of the Progress of the H uman Mind. London, UK: Weidenfeld \& Nicolson

D rucker PF (1993) Post-capitalist Society. N ew York, NY, USA: Harper \& Row

Fukuyama F (2002) O ur Posthuman Future: Consequences of the Biotechnology Revolution. N ew York, NY, USA: Farrar, Straus \& Giroux

H araway DJ (1991) Simians, Cyborgs, and Women. N ew York, NY, U SA: Routledge Heidegger M (1962) Being and Time. N ew York, NY, USA: Harper \& Row

Knorr Cetina K (1997) Sociality with objects. Social relations in postsocial knowledge societies. Theory, Culture Soc 14: 1-30 Lash S (2003) Empire and Vitalism. Philadelphia, PA, USA: Proceedings of the Annual M eeting of the Eastern Sociological Society

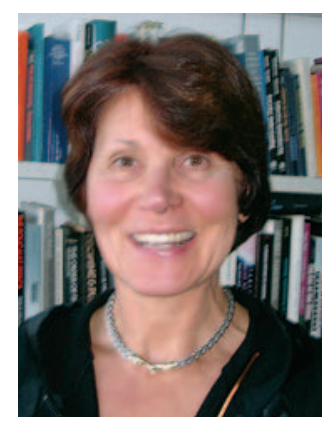

Karin Knorr Cetina is Professor of Sociology at the University of Konstanz, Germany. E-mail:karin.knorr@uni-konstanz.de

doi :10.1038/sj.embor.7400437 